\title{
Synthesis of KCC-1 Using Rice Husk Ash for Pb Removal from Aqueous Solution and Petrochemical Wastewater
}

\author{
Rosalyza Hasan ${ }^{1}$, Chi Cheng Chong ${ }^{1}$, Herma Dina Setiabudi ${ }^{1,2, *}$ \\ ${ }^{1}$ Faculty of Chemical and Natural Resources Engineering, Universiti Malaysia Pahang, 26300 \\ Gambang, Kuantan, Pahang, Malaysia \\ ${ }^{2}$ Centre of Excellence for Advanced Research in Fluid Flow, Universiti Malaysia Pahang, 26300 \\ Gambang, Kuantan, Pahang, Malaysia
}

Received: 15th November 2018; Revised: 1st January 2019; Accepted: th $^{\text {th }}$ January 2019;

Available online: 25th January 2019; Published regularly: April 2019

\begin{abstract}
A silica-rich rice husk ash (RHA, 95.44\% $\mathrm{SiO}_{2}$ ) was used as a silica precursor in the synthesis of KCC-1 for $\mathrm{Pb}$ (II) removal. The extraction of silica was carried out under several extraction methods (alkali fusion (AF), reflux (RF) and microwave heating (MW)) and extraction parameters (NaOH/RHA mass ratio, fusion temperature and $\mathrm{H}_{2} \mathrm{O} / \mathrm{NaOH}$-fused RHA mass ratio). The highest silica content was obtained using $\mathrm{AF}$ method at extraction conditions of $\mathrm{NaOH} / \mathrm{RHA}$ mass ratio $=2$, fusion temperature $=$ $550{ }^{\circ} \mathrm{C}$, and $\mathrm{H}_{2} \mathrm{O} / \mathrm{NaOH}$-fused $\mathrm{RHA}$ mass ratio $=4$, with silica concentration of 85,490 ppm. TEM, FTIR, and BET analyses revealed the synthesized KCC-1 has fibrous morphology with surface area of $220 \mathrm{~m}^{2} / \mathrm{g}$. The synthesized KCC-1 showed good performance in removal of $\mathrm{Pb}$ (II) from aqueous solution (74\%) and petrochemical wastewater $(70 \%)$. The analyses of petrochemical wastewater revealed that the adsorption process using synthesized KCC-1 effectively decreased the concentration of COD (489 $\mathrm{mg} / \mathrm{L}$ to $106 \mathrm{mg} / \mathrm{L})$, BOD $(56 \mathrm{mg} / \mathrm{L}$ to $34 \mathrm{mg} / \mathrm{L})$ and $\mathrm{Pb}(\mathrm{II})(22.8 \mathrm{mg} / \mathrm{L}$ to $6.71 \mathrm{mg} / \mathrm{L})$. This study affirmed that KCC-1 was successfully synthesized using RHA as silica precursor and applied as an efficient adsorbent for $\mathrm{Pb}$ (II) removal. Copyright (C) 2019 BCREC Group. All rights reserved
\end{abstract}

Keywords: Rice husk ash (RHA); Alkali fusion; Lead; Adsorption

How to Cite: Hasan, R., Chong, C.C., Setiabudi, H.D. (2019). Synthesis of KCC-1 Using Rice Husk Ash for Pb Removal from Aqueous Solution and Petrochemical Wastewater. Bulletin of Chemical Reaction Engineering \& Catalysis, 14 (1): 196-204 (doi:10.9767/bcrec.14.1.3619.196-204)

Permalink/DOI: https://doi.org/10.9767/bcrec.14.1.3619.196-204

\section{Introduction}

The issue of disposal of various pollutants into wastewater has been emerged with the rapid industrialization over these decades, with the heavy metals contributed to the largest sorts and even hardest to be treated. Lead $(\mathrm{Pb}(\mathrm{II}))$ undoubtedly as the most problematic element which brought adverse impacts to this ecosystem [1]. Even in a mild quantity, $\mathrm{Pb}$ (II)

* Corresponding Author.

E-mail: herma@ump.edu.my (H.D. Setiabudi),

Tel.: +60-9-5492836, Fax: +60-9-5492889 can resulted in severe neurological and physiological consequences to human beings [1]. Once this element has been ingested exceeded the allowable concentration, it tends to accumulate in the human body, and consequently cause serious health disorders [2]. The widespread of $\mathrm{Pb}$ (II) in the ecosystem devoted to the efforts of investigating the most efficient technique to eliminate $\mathrm{Pb}$ (II) from contaminated water. There are several well-documented and widely applied heavy metals removal techniques such as precipitation stabilization [3], ion exchange [4], coagulation-flocculation [5], and adsorption [6-9]. Generally, the simplicity design, technical 
user friendly and cost effectiveness would be the key considerations for treatment selection [10].

In recent years, a considerable number of researches have been devoted the application of mesoporous silica materials as adsorbent due to their well-ordered structure and high surface area [11,12]. In 2010, a novel mesoporous silica, namely, fibrous silica nanosphere (KCC-1) with unique spherical shape and high surface area was discovered [13]. Unlike the typical pore-based silica materials, KCC-1 is surrounded by vast amount of dendrimer, thus form fibrous morphology on it [14]. The unique morphology of KCC-1 renders abundant accessible active sites, which subsequently enhance its performance towards several applications [15]. The impressive physical properties of KCC-1, induced the attempt to remove $\mathrm{Pb}$ (II) by using KCC-1 as adsorbent. Nonetheless, the involvement of relatively expensive commercial silica precursor during KCC-1 preparation such as tetraethyl orthosilicate $\left(\mathrm{SiC}_{8} \mathrm{H}_{20} \mathrm{O}_{4}\right.$, TEOS) and sodium silicate $\left(\mathrm{Na}_{2} \mathrm{SiO}_{3}\right)$, gave the idea of seeking alternative silica source.

In the meantime, low cost and high availability agricultural by-products which owned high silica content would be a good choice. Rice husk, which known to be invaluable agro-based waste accounts for 545 million metric tons (roughly one-fifth of the annual yield of rice around the world) [16]. Factories tend to combust the rice husk due to the overwhelming availability of this rice husk to form rice husk ash (RHA) and dumped by landfilling. Since RHA was disposed in an uneconomical way, the utilization of RHA as silica precursor in KCC-1 preparation seem to be an attractive approach. Thus, in this study, RHA was used as silica precursor for KCC-1 and the performance of synthesized KCC-1 was analyzed for Pb(II) removal from aqueous solution and wastewater.

\section{Materials and Method}

\subsection{Extraction of Sodium Silicate from Rice Husk Ash (RHA)}

The rice husk ash (RHA) was collected from Kedah, Malaysia. Prior to the extraction process, acid leaching process was carried out by adding $10 \mathrm{~g}$ of RHA into $2 \mathrm{M} \mathrm{HCl}$ solution (100 $\mathrm{mL}$ ), followed by stirring at $60{ }^{\circ} \mathrm{C}$ for $3 \mathrm{~h}$. The mixture was filtered, and the collected filtride was washed with distilled water, oven-dried $\left(120{ }^{\circ} \mathrm{C}\right)$ and calcined $\left(550{ }^{\circ} \mathrm{C}, 3 \mathrm{~h}\right)$. The obtained sample was named as acid-leached RHA (A-RHA). The composition of RHA and A-RHA was analysed using XRF.
The solution of sodium silicate from rice husk ash ( $\left.\mathrm{Na}_{2} \mathrm{SiO}_{3}-\mathrm{RHA}\right)$ was prepared using A-RHA via several preparation methods (alkali fusion (AF) method, reflux (RF) method, and microwave heating (MW) method). For the AF method, the $\mathrm{Na}_{2} \mathrm{SiO}_{3}$ - $\mathrm{RHA}$ was prepared according to the method reported by Yilmaz and Piskin [17] with some modification. In brief, ARHA (30 g) was mixed with sodium hydroxide (30 g, NaOH, Merck), followed by calcination $\left(550{ }^{\circ} \mathrm{C}, 1 \mathrm{~h}\right)$ to form $\mathrm{NaOH}$-fused RHA. The powder form of $\mathrm{NaOH}$-fused RHA was mixed with deionized water and stirred for $24 \mathrm{~h}$ at room temperature. Then, the solution was filtered to obtain the filtrate $\left(\mathrm{Na}_{2} \mathrm{SiO}_{3}-\mathrm{RHA}\right)$. For the $\mathrm{RF}$ method, the $\mathrm{Na}_{2} \mathrm{SiO}_{3}$ - $\mathrm{RHA}$ was prepared according to the method reported by Nayak and Bera [18] with some modification. In brief, A-RHA ( $30 \mathrm{~g}$ ) was mixed with a solution of $\mathrm{NaOH}$ ( $30 \mathrm{~g} \mathrm{NaOH}$ powder dissolving in $60 \mathrm{~mL}$ of deionized water), followed by heating for $3 \mathrm{~h}$ at $100{ }^{\circ} \mathrm{C}$. The solution was stirred at room temperature for another $24 \mathrm{~h}$, followed by filtration to obtain the filtrate $\left(\mathrm{Na}_{2} \mathrm{SiO}_{3}-\mathrm{RHA}\right)$. Meanwhile, for the MW method, $\mathrm{Na}_{2} \mathrm{SiO}_{3}$ - $\mathrm{RHA}$ was prepared by referring to Kumchompoo et al. [19] with some modification. In brief, ARHA (30 g) was mixed with a solution of $\mathrm{NaOH}$ (30 g NaOH powder dissolving in $60 \mathrm{~mL}$ of deionized water). The mixture was then being heated under microwave irradiation $(600 \mathrm{~W})$ at $100{ }^{\circ} \mathrm{C}$ for $5 \mathrm{~min}$. The solution was stirred at room temperature for another $24 \mathrm{~h}$, followed by filtration to obtain the filtrate $\left(\mathrm{Na}_{2} \mathrm{SiO}_{3}-\mathrm{RHA}\right)$. All the $\mathrm{Na}_{2} \mathrm{SiO}_{3}$ - $\mathrm{RHA}$ were analysed using inductively coupled plasma mass spectrometry (ICP-MS) (Agilent 7500 Series), and the optimal amount of $\mathrm{Na}_{2} \mathrm{SiO}_{3}$-RHA solution was used for the KCC-1 preparation.

\subsection{Preparation of KCC- 1}

KCC-1 was prepared according to Le et al. [13] with some modification. In brief, $\mathrm{Na}_{2} \mathrm{SiO}_{3}$ RHA, butanol (Merck, $1.5 \mathrm{~mL}$ ), and toluene (Merck, $30 \mathrm{~mL}$ ) were mixed in one beaker, whereas urea (Merck, $0.6 \mathrm{~g}$ ), cetyltriammonium bromide (CTAB, Aldrich, $1 \mathrm{~g}$ ), and water $(30 \mathrm{~mL})$ were mixed in another beaker. Then, both solutions were mixed and stirred $\left(30^{\circ} \mathrm{C}\right.$, $45 \mathrm{~min}$ ) before being heated in a Teflon-sealed hydrothermal reactor $\left(120^{\circ} \mathrm{C}, 5 \mathrm{~h}\right)$. The obtained solution was centrifuged, rinsed using distilled water, oven-dried $\left(100{ }^{\circ} \mathrm{C}, 12 \mathrm{~h}\right)$, and calcined $\left(550^{\circ} \mathrm{C}, 5 \mathrm{~h}\right)$ to produce the KCC-1.

\subsection{Characterization of KCC-1}

The morphology of the synthesized KCC-1 
was determined using Transmission Electron Microscopy (TEM Leo Libra-120). The functional groups were examined by FourierTransform Infrared (FTIR Spectrometer Nicolet iS5, Thermo Scientific) in the range of 4000 to $400 \mathrm{~cm}^{-1}$. The textural properties of KCC-1 were analysis using Bruneuer-EmmettTeller (BET) (Micromeritics $\left.{ }^{\circledR}\right)$ at $77 \mathrm{~K}$.

\subsection{Petrochemical Wastewater Analyses}

Petrochemical wastewater was collected from Petrochemical Industry located in $\mathrm{Pa}$ hang, Malaysia. The sample was analysed using ICP-MS (Agilent 7500 Series) to determine the concentration of heavy metals in the wastewater. Chemical Oxygen Demand (COD) analysis was carried out using DRB200 Reactor. Prior to the COD analysis, reagent was prepared using sulphuric acid $(250 \mathrm{~mL})$, distilled water $(50 \mathrm{~mL})$, potassium dichromate $(2.4 \mathrm{~g})$, mercuric sulphate $(5 \mathrm{~g})$ and argentum sulphate (4 g) [20]. The COD test was carried out by mixing the specific amount of reagent and wastewater, followed by preheated in DRB200 Reactor for $2 \mathrm{~h}$ at $150^{\circ} \mathrm{C}$. Then, the sample was analysed after cool down to room temperature. Biochemical Oxygen Demand (BOD) analysis was carried out using Dissolved Oxygen Meter (AZ-8403) with 5-day BOD standard method as reported by APHA_AWWA_WEF (2012).

Table 1. XRF Analysis of RHA and A-RHA

\begin{tabular}{ccc}
\hline Parameter & RHA (\%) & A-RHA (\%) \\
\hline $\mathrm{SiO}_{2}$ & 88.52 & 95.44 \\
$\mathrm{~K}_{2} \mathrm{O}$ & 5.783 & 2.43 \\
$\mathrm{P}_{2} \mathrm{O}_{5}$ & 2.76 & 1.02 \\
$\mathrm{CaO}$ & 1.35 & 0.54 \\
$\mathrm{MgO}$ & 0.46 & 0.18 \\
$\mathrm{Cl}$ & 0.40 & 0.18 \\
$\mathrm{SO}_{3}$ & 0.24 & 0.00 \\
$\mathrm{Fe}_{2} \mathrm{O}_{3}$ & 0.16 & 0.10 \\
$\mathrm{MnO}_{\mathrm{Al}} \mathrm{O}_{3}$ & 0.14 & 0.08 \\
$\mathrm{ZnO}$ & 0.08 & 0.00 \\
$\mathrm{Rb}_{2} \mathrm{O}$ & 0.04 & 0.01 \\
$\mathrm{SrO}$ & 0.02 & 0.01 \\
$\mathrm{CuO}$ & 0.01 & 0.01 \\
$\mathrm{NiO}$ & 0.01 & 0.01 \\
\hline & 0.01 & 0.00 \\
\hline
\end{tabular}

\subsection{Adsorption Process}

Batch adsorption experiments were executed on the $\mathrm{Pb}$ (II) removal from aqueous solution and petrochemical wastewater. For the case of $\mathrm{Pb}$ (II) aqueous solution, dissolution of an exact quantity of $\mathrm{Pb}$ (II) nitrate $\left(\mathrm{Pb}\left(\mathrm{NO}_{3}\right)_{2}\right.$, Sigma-Aldich) in deionized water was carried out to prepare the stock solution. Thereafter, 1 $\mathrm{g} / \mathrm{L}$ of KCC-1 was added to the $\mathrm{Pb}$ (II) solution $(50 \mathrm{mg} / \mathrm{L})$ under constant stirring at ambient temperature. Then, the samples were collected, centrifuged (3000 rpm, 2 min), and analysed using UV-vis spectroscopy at $520 \mathrm{~nm}$. Similar procedure was carried out for petrochemical wastewater except for the preparation of stock solution.

The amount of $\mathrm{Pb}$ (II) adsorbed and $\mathrm{Pb}$ (II) removal percentage were computed using following equation:

$$
\begin{aligned}
& q_{t}=\left(\frac{C_{o}-C_{t}}{m}\right) \times V \\
& \text { Removal }(\%)=\left(\frac{C_{o}-C_{t}}{C_{o}}\right) \times 100
\end{aligned}
$$

where $q_{t}(\mathrm{mg} / \mathrm{g})$ stands for the value of $\mathrm{Pb}$ (II) adsorbed at particular time, $C_{o}$ and $C_{t}(\mathrm{mg} / \mathrm{L})$ represent the initial concentration and the liquid-phase concentration of $\mathrm{Pb}$ (II) solution at particular time, respectively, $V(\mathrm{~L})$ stands for the volume of the $\mathrm{Pb}(\mathrm{II})$ solution and $m(\mathrm{~g})$ refers to the mass of KCC-1.

\subsection{Regeneration and Reusability}

The regeneration and reusability of the synthesized KCC-1 was studied using four consecutive adsorption-desorption cycles with 0.1 $\mathrm{M} \mathrm{HNO}_{3}$ as desorbing agent.

\section{Result and Discussion}

\subsection{Pre-treatment of Rice Husk Ash}

Table 1 shows the oxide groups in RHA with and without acid leaching treatment. From the result shown in Table 1, silica $\left(\mathrm{SiO}_{2}\right)$ is the major component in both RHA indicating the high suitability of RHA as silica precursor for KCC-1 synthesis. By comparing the percentage of $\mathrm{SiO}_{2}$ in RHA and A-RHA, it was clearly observed that the pre-treatment of RHA with $\mathrm{HCl}$ was improved the purity of $\mathrm{SiO}_{2}$ by removing the metallic impurities in RHA. The presence of chloride ion ( $\mathrm{Cl}$-) in $\mathrm{HCl}$ attracted the metallic element to form salts, which can be easily dissolved and removed by filtration [21]. 
The positive role of acid leaching in removing the metallic impurities of RHA was also reported by Bakar et al. with an increase in $\mathrm{SiO}_{2}$ purity from $95.77 \%$ to $99.58 \%$ [22].

\subsection{Sodium Silicate Preparation from Rice Husk Ash ( $\left.\mathrm{Na}_{2} \mathrm{SiO}_{3}-\mathrm{RHA}\right)$}

Figure 1 shows the influence of extraction method on the concentration of extracted silica. The amount of the silica content in $\mathrm{Na}_{2} \mathrm{SiO}_{3}$ RHA in a sequence of $\mathrm{AF}>\mathrm{RF}>\mathrm{MW}$, indicating the excellent performance of $\mathrm{AF}$ method in the extraction process. An excellent performance of AF method was also reported by Shoppert et al. [23], owing to its high silica concentration, efficient and energy-saving. Since AF method was found as a best method for extraction process, this method was used to identify the best extraction conditions.

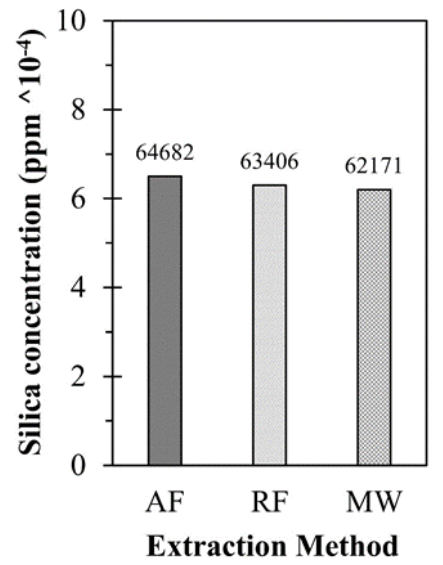

Figure 1. The silica concentration versus extraction method. Condition: $\mathrm{NaOH} / \mathrm{RHA}=1: 1$; $T=550{ }^{\circ} \mathrm{C}$, and $\mathrm{H}_{2} \mathrm{O} / \mathrm{NaOH}$-fused $\mathrm{RHA}=2: 1$.
Several extraction parameters including $\mathrm{NaOH} / \mathrm{RHA}$ mass ratio (5:1, 1:1, 2:1 and 3:1), fusion temperature $\left(500,550,600\right.$ and $\left.700{ }^{\circ} \mathrm{C}\right)$ and $\mathrm{H}_{2} \mathrm{O} / \mathrm{NaOH}$-fused RHA mass ratio (1:1, 2:1, 4:1 and 5:1) were studied to identify the highest amount of silica concentration. Figure 2(A) shows the effect of $\mathrm{NaOH} / \mathrm{RHA}$ mass ratio towards extracted silica concentration. An increase in the mass ratio of $\mathrm{NaOH} / \mathrm{POFA}$ resulted to an increase in extracted silica concentration, passing through the optimum at 2 , and decreased at elevated mass ratio $\mathrm{NaOH} / \mathrm{RHA}$. This result might be related with the changes in the $\mathrm{pH}$ of solution, and thus altering the silica dissolution process in aqueous solution which predominantly caused by the hydrolysis of $\mathrm{Si}-\mathrm{O}-\mathrm{Si}$ bonds [24]. Similar trend was reported by Keawthun et al. [25] for conversion of waste glasses into sodium silicate solutions.

Figure 2(B) shows the effect of the AF temperature towards extracted silica concentration. According to the plot, it was observed that increasing in $\mathrm{AF}$ temperature up to $550{ }^{\circ} \mathrm{C}$, increased the concentration of extracted silica and slightly decreased at elevated temperature. The similar optimum fusion temperature $\left(550{ }^{\circ} \mathrm{C}\right)$ was also reported by Yilmaz and Piskin [17] for the extraction of silica from tailings slurry of gold mine treatment plant by AF method. They reported that the most suitable fusion temperature is $550{ }^{\circ} \mathrm{C}$ and higher fusion temperature will lead to the degradation of chemical compounds and consequently decrease the silica extraction efficiency.

Figure 2(C) displays the effect of mass ratio of $\mathrm{H}_{2} \mathrm{O} / \mathrm{NaOH}$-fused RHA towards the concentration of extracted silica. An increase in the mass ratio of $\mathrm{H}_{2} \mathrm{O} / \mathrm{NaOH}$-fused $\mathrm{RHA}$ resulted
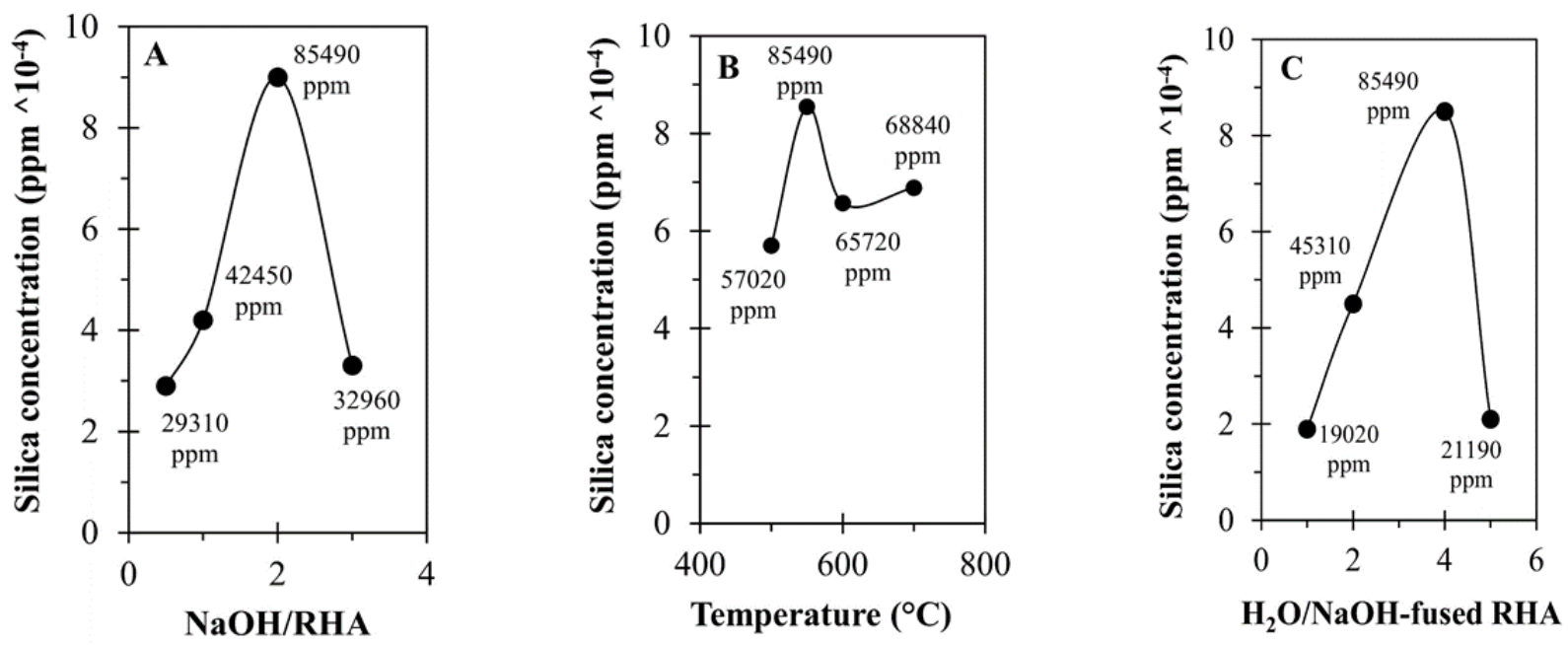

Figure 2. Concentration of extracted silica at different effect of (A) NaOH/RHA mass ratio; (B) fusion temperature; and (C) $\mathrm{H}_{2} \mathrm{O} / \mathrm{NaOH}$-fused $\mathrm{RHA}$ mass ratio. 
to an increase in extracted silica concentration, passing through the optimum at 4 , and decreased at elevated mass ratio. Silva et al. [26] reported that the lower ratio of $\mathrm{H}_{2} \mathrm{O} / \mathrm{NaOH}$ fused RHA would decrease the concentration of sodium, which can be claimed on the highly viscous solution worsen the leaching process. Similar trend was also reported by Shelke et al. [27] for the extraction of silica from RHA.

From the results observed in Figure 2, the best extraction conditions were achieved at mass ratio of 2 , fusion temperature of $550{ }^{\circ} \mathrm{C}$ and $\mathrm{H}_{2} \mathrm{O} / \mathrm{NaOH}$-fused RHA mass ratio of 4 .

\subsection{Characterization of KCC-1 Synthesized from RHA}

Figure 3 shows the TEM image of KCC-1 synthesized from RHA. As illustrated from the figure, the sample was spherical in shape and covered with the fibrous morphology. The TEM image of the synthesized KCC-1 was in conformity with literature $[15,28]$.

The $\mathrm{N}_{2}$ physisorption analysis revealed that the synthesized KCC-1 possesses BET surface area $\left(S_{B E T}\right)$ of $220 \mathrm{~m}^{2} / \mathrm{g}$, pore size $\left(d_{p}\right)$ of 17.37 $\mathrm{nm}$, and pore volume $\left(V_{p}\right)$ of $0.94 \mathrm{~cm}^{3} / \mathrm{g}$. As compared to the literature [29], the synthesized KCC-1 has relatively lower $S_{B E T}$ as compared to the literature $\left(386 \mathrm{~m}^{2} / \mathrm{g}\right)$ that synthesized using TEOS, might be caused by the impurities that existing in RHA, thus, affected the KCC-1 structure [30]. This study was in agreement with Wang et al. [30] whom reported that the textural properties of SBA-15 synthesized using coal gangue $\left(S_{B E T}=552 \mathrm{~m}^{2} / \mathrm{g}, d_{p}=7.0 \mathrm{~nm}\right.$, and $V_{p}=0.54 \mathrm{~cm}^{3} / \mathrm{g}$ ) was lower than that of

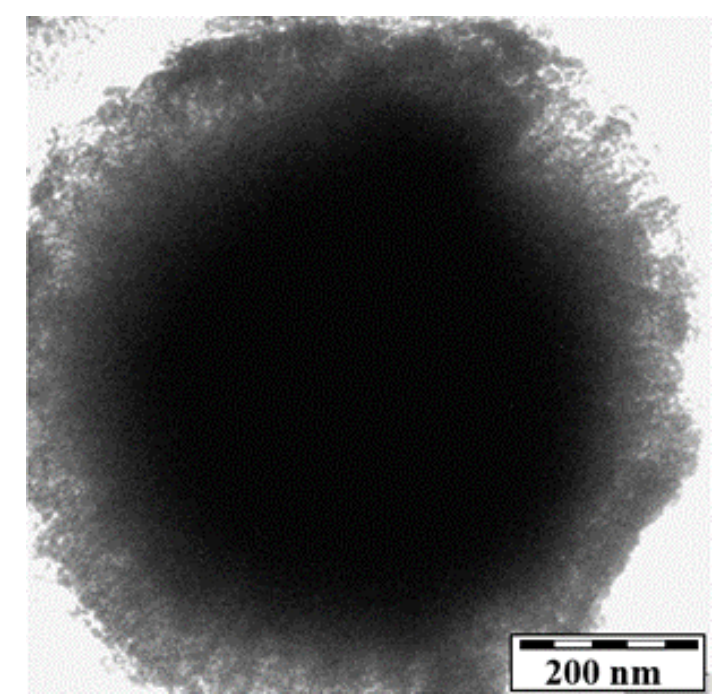

Figure 3. TEM image of KCC-1 synthesized from RHA.
SBA-15 synthesized using commercial sodium silicate $\left(S_{B E T}=567 \mathrm{~m}^{2} / \mathrm{g}, d_{p}=7.2 \mathrm{~nm}\right.$, and $V_{p}=$ $0.68 \mathrm{~cm}^{3} / \mathrm{g}$ ), due to the impurities present in coal gangue.

The functional groups present in KCC-1 synthesized from RHA were analysed using FTIR, as shown in Figure 4. The spectra shows several bands at approximately $3423 \mathrm{~cm}^{-1}$, $1058 \mathrm{~cm}^{-1}, 800 \mathrm{~cm}^{-1}$, and $450 \mathrm{~cm}^{-1}$, which ascribed to the $\mathrm{O}-\mathrm{H}$ stretching vibration of $\mathrm{Si}$ $\mathrm{OH}$, Si-O asymmetrical stretching, Si-O symmetrical stretching, and bending of Si-O, respectively [31]. Similar peaks were also reported by Dong et al. (2015) for modified fibrous silica nanospheres [32], signifying the successful formation of KCC-1 structure from RHA as silica precursor.

3.4 Adsorption Performance of KCC-1 Synthesized from RHA

The adsorption performance of synthesized KCC-1 on $\mathrm{Pb}$ (II) removal was evaluated using aqueous solution and petrochemical wastewater and the results are shown in Figure 5 . KCC-1 was proven to have high feasibility as adsorbent for $\mathrm{Pb}(\mathrm{II})$ removal as demonstrated in its high removal percentage (74\% (aqueous), $70 \%$ (wastewater)), owing to its favourable structural properties. In addition, the analyses of wastewater (Table 2) clearly showed that the synthesized KCC-1 effectively reduced the COD, BOD, and heavy metals concentration of the wastewater, indicating an excellent performance of KCC-1 in adsorption process. An excellent performance of synthesized KCC-1 in $\mathrm{Pb}$ (II) removal (74\%, $37.26 \mathrm{mg} / \mathrm{g})$ can be proved

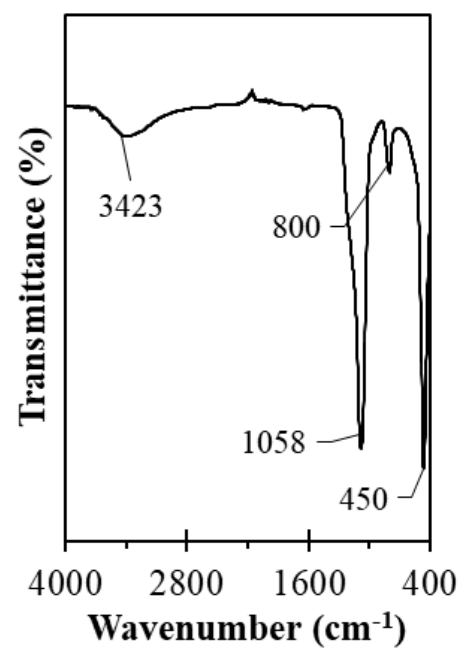

Figure 4. FTIR spectra of KCC-1 synthesized from RHA. 
by the comparison of the KCC-1's performance with other reported adsorbent as listed in Table 3.

Figure 6 shows the regeneration and reusability of synthesized KCC-1 during four consecutive adsorption-desorption cycles. KCC-1 shows excellent performance during adsorption-desorption cycles with moderate decreased in the percentage of $\mathrm{Pb}(\mathrm{II})$ removal. The de-

Table 2. Petrochemical wastewater analysis before and after the adsorption process using KCC-1 synthesized from RHA.

\begin{tabular}{ccc}
\hline Parameter & Before $(\mathrm{mg} / \mathrm{L})$ & After $(\mathrm{mg} / \mathrm{L})$ \\
\hline COD & 489 & 106 \\
BOD & 56 & 34 \\
Sodium $(\mathrm{Na})$ & 60.9 & 26.9 \\
Potassium $(\mathrm{K})$ & 21.9 & Not detected \\
Calcium $(\mathrm{Ca})$ & 4.2 & 3.34 \\
Magnesium $(\mathrm{Mg})$ & 0.3 & 0.20 \\
Copper $(\mathrm{Cu})$ & 0.0852 & Not detected \\
Aluminium $(\mathrm{Al})$ & 0.0049 & Not detected \\
Vanadium $(\mathrm{V})$ & 0.0031 & Not detected \\
Manganese $(\mathrm{Mn})$ & 0.032 & Not detected \\
Nickel $(\mathrm{Ni})$ & 0.0072 & Not detected \\
Chromium $(\mathrm{Cr})$ & $<0.0005$ & Not detected \\
Arsenic $(\mathrm{As})$ & $<0.0005$ & Not detected \\
Selenium $(\mathrm{Se})$ & $<0.0005$ & Not detected \\
Molybdenum $(\mathrm{Mo})$ & 0.936 & Not detected \\
Silver $(\mathrm{Ag})$ & $<0.0005$ & Not detected \\
Cadmium $(\mathrm{Cd})$ & 0.0352 & Not detected \\
Antimony $(\mathrm{Sb})$ & 0.0017 & Not detected \\
Barium $(\mathrm{Ba})$ & $<0.0005$ & Not detected \\
Lead $(\mathrm{Pb})$ & 22.8 & 6.71 \\
\hline
\end{tabular}

clined in the adsorption performance with increasing in the number of cycles might be due to the blockage of some active sites available on the KCC-1's surface, owing to the partial desorption of $\mathrm{Pb}(\mathrm{II})$ molecules during the regeneration process [39]. The decreased in the adsorption performance of the synthesized KCC-1 ( $20 \%$ for aqueous solution, $34 \%$ for wastewater, 4 cycles) during consecutive adsorptiondesorption cycles was lower as compared to the reported literatures for modified potato starchmagnetic nanoparticles (MPS-MNPs) (50\%, 4 cycles) [40] and nanoscale zero-valent iron immobilized in alginate microcapsules $(60 \%, 4 \mathrm{cy}$ cles) [41], implying good performance of synthesized KCC-1 in $\mathrm{Pb}$ removal.

The spent KCC-1 was analysed using FTIR spectroscopy and was compared with the fresh KCC-1 for identifying the functional groups

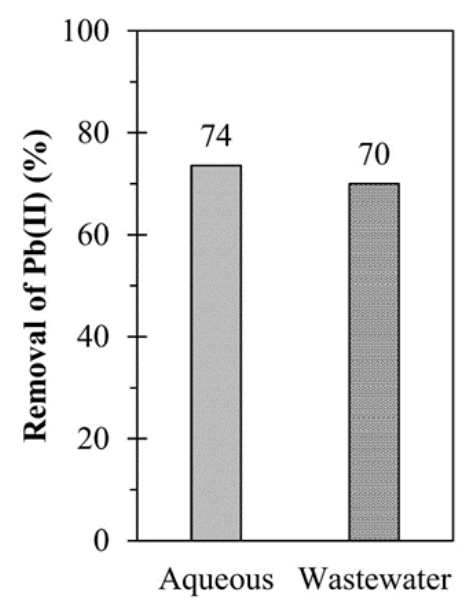

Figure 5. Removal percentage of $\mathrm{Pb}(\mathrm{II})$ from aqueous solution and petrochemical wastewater using KCC-1 synthesized from RHA. Conditions: $C_{\text {o, aqueous }}=50 \mathrm{mg} / \mathrm{L}, m_{\mathrm{KCC}-1}=1 \mathrm{~g} / \mathrm{L}, \mathrm{pH}=$ 6 , and time $=80 \mathrm{~min}$.

Table 3. Comparison of adsorption capacity for KCC-1 with other reported adsorbents in $\mathrm{Pb}$ (II) removal.

\begin{tabular}{lcc}
\hline \multicolumn{1}{c}{ Adsorbent } & $\begin{array}{c}\text { Adsorption capacity } \\
(\mathrm{mg} / \mathrm{g})\end{array}$ & Ref \\
\hline KCC-1 synthesized from RHA & 37.26 & This study \\
MCM-41-S9 & 34.33 & {$[33]$} \\
Diatomite & 26.00 & {$[34]$} \\
Silica Gel & 14.42 & {$[35]$} \\
Phenol-formaldehyde/silicon dioxide resin (PFSR) & 13.74 & {$[36]$} \\
Mercapto-modified silica particles & 10.42 & {$[37]$} \\
Anionic layered double hydroxide (LDH) & 6.81 & {$[38]$} \\
\hline
\end{tabular}


that responsible for the adsorption process (Figure 7). It was observed that the FTIR peaks of the synthesized KCC-1 (3423 $\mathrm{cm}^{-1}, 1058 \mathrm{~cm}^{-1}$, $800 \mathrm{~cm}^{-1}$, and $450 \mathrm{~cm}^{-1}$ ) were shifted after the adsorption process due to the electrostatic and chemical interaction of functional groups with metal ions [42]. The significant alteration of $3423 \mathrm{~cm}^{-1}$, in terms of the wavenumber and intensity might be related to the $\mathrm{Pb}$ molecules' interaction with $\mathrm{Si}-\mathrm{O}-\mathrm{H}$ of $\mathrm{KCC}-1$ to form the $\mathrm{Si}-\mathrm{O}-\mathrm{Pb}$.

\section{Conclusion}

The potential of KCC-1 synthesized from rice husk ash (RHA) was tested on $\mathrm{Pb}(\mathrm{II})$ removal from aqueous and petrochemical wastewater. Prior to the extraction process, acid treatment was executed to enhance the purity of silica, $\mathrm{SiO}_{2}$ by elimination the metallic impurities in RHA. The study of extraction methods (alkali fusion (AF), reflux (RF) and microwave heating (MW)) and extraction parameters ( $\mathrm{NaOH} / \mathrm{RHA}$ mass ratio, fusion temperature and $\mathrm{H}_{2} \mathrm{O} / \mathrm{NaOH}$-fused RHA mass ratio) revealed that the highest silica content was obtained using $\mathrm{AF}$ method at extraction conditions of $\mathrm{NaOH} / \mathrm{RHA}$ mass ratio $=2$, fusion temperature $=550{ }^{\circ} \mathrm{C}$, and $\mathrm{H}_{2} \mathrm{O} / \mathrm{NaOH}$-fused $\mathrm{RHA}$ mass ratio $=4$, with silica concentration of $85,490 \mathrm{ppm}$. The characterization analyses (TEM, BET and FTIR) of synthesized KCC-1 in conformity with literature, signifying the successful formation of KCC-1 structure from RHA. The performance studies showed that the synthesized KCC-1 has a good performance in $\mathrm{Pb}$ (II) removal from aqueous (74\%) and petrochemical wastewater $(70 \%)$, with moderate reduction in the percentage of $\mathrm{Pb}(\mathrm{II})$ removal
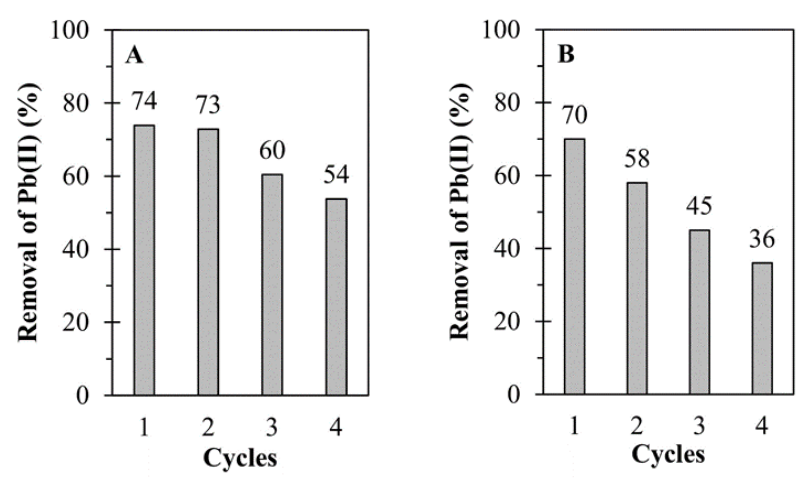

Figure 6. Reusability of KCC-1 synthesized from $\mathrm{RHA}$ during $\mathrm{Pb}$ (II) removal from (A) aqueous solution and (B) petrochemical wastewater. Conditions: $C_{o \text {,aqueous }}=50 \mathrm{mg} / \mathrm{L}, m_{K C C-1}=$ $1 \mathrm{~g} / \mathrm{L}$, and time $=80 \mathrm{~min}$. during adsorption-desorption cycles. The wastewater analyses (COD, BOD and ICP-MS) revealed an excellent performance of KCC-1 as demonstrated by a significant decrease in the COD (489 mg/L to $106 \mathrm{mg} / \mathrm{L})$, BOD $(56 \mathrm{mg} / \mathrm{L}$ to $34 \mathrm{mg} / \mathrm{L})$, and $\mathrm{Pb}(\mathrm{II})$ concentration $(22.8 \mathrm{mg} / \mathrm{L}$ to $6.71 \mathrm{mg} / \mathrm{L}$ ).

\section{Acknowledgement}

The authors are grateful for the financial support from Universiti Malaysia Pahang, Malaysia through Research University Grant (RDU170331) and Postgraduate Research Grants Scheme (PGRS180305).

\section{References}

[1] Brooks, R.M., Bahadory, M., Tovia, F., Rostami, H. (2010). Removal of lead from contaminated water. International Journal of Soil, Sediment and Water, 3(2): 1-14.

[2] Babel, S., Kurniawan, T.A. (2003). Low-cost adsorbents for heavy metals uptake from contaminated water: a review. Journal of Hazardous Material, 97(1-3): 219-243.

[3] Kavak, D. (2013). Removal of lead from aqueous solutions by precipitation: Statistical analysis and modeling. Desalination and $\mathrm{Wa}$ ter Treatment, 51(7-9):1720-1726.

[4] Al-Enezi, G., Hamoda, M.F., Fawzi, N. (2004). Ion Exchange Extraction of Heavy Metals from Wastewater Sludges. Journal of Environmental Science and Health - Part A, 39(2): 455-464..

[5] Johnson, P.D., Girinathannair, P., Ohlinger, K.N., Ritchie, S., Teuber, L., Kirby, J. (1999). Enhanced Removal of Heavy Metals in Primary Treatment Using Coagulation and Floc-

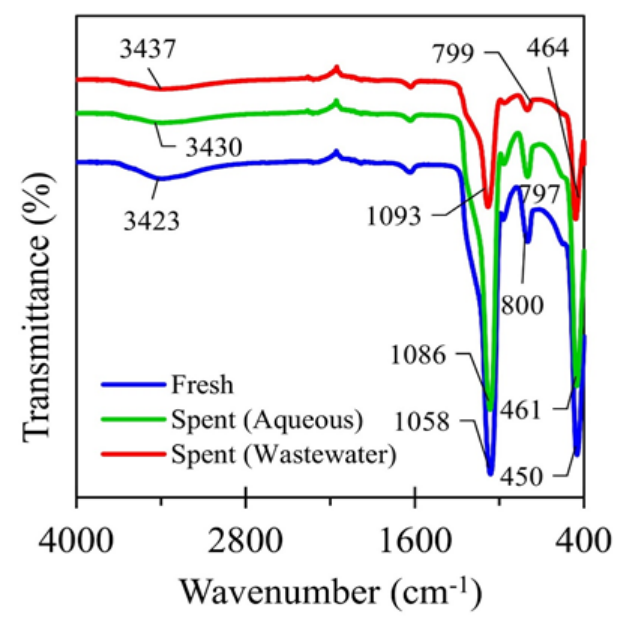

Figure 7. FTIR spectra of fresh and spent KCC-1 synthesized from RHA. 
culation, Water environment research, 80(5): 80-85.

[6] Yabe, M.J.S., de Oliveira E. (2003). Heavy metals removal in industrial effluents by sequential adsorbent treatment. Advance Environmental Resources, 7(2): 263-272.

[7] Hadioui, M., Sharrock, P., Mecherri, M.O., Brumas, V., Fiallo, M. (2008). Reaction of lead ions with hydroxylapatite granules. Chemical Paper, 62(5): 516-521.

[8] Von Lindern, I.V., Spalinger, S., Petroysan, V., Von Braun, M. (2003). Assessing remedial effectiveness through the blood lead:soil/dust lead relationship at the Bunker Hill Superfund Site in the Silver Valley of Idaho. Science of the Total Environment, 303(1-2): 139170.

[9] Leighton, J., Klitzman, S., Sedlar, S., Matte T., Cohen, N.L. (2003). The effect of leadbased paint hazard remediation on blood lead levels of lead poisoned children in New York City. Environmental Resources, 92(3): 182190.

[10] Eccles, H. (1999). Treatment of metalcontaminated wastes: Why select a biological process?. Trends Biotechnology, 17(12): 462465.

[11] Fu, F., Wang, Q. (2011). Removal of heavy metal ions from wastewaters: A review. Journal of Environmental Management, 92(3): 407-418.

[12] Walcarius, A., Etienne, M., Sayen, S., Lebeau, B. (2003).Grafted silicas in electroanalysis: Amorphous versus ordered mesoporous materials. Electroanalysis: An International Journal Devoted to Fundamental and Practical Aspects of Electroanalysis, 15(5-6): 414-421.

[13] Le X., Dong Z., X. Li, Zhang W., Le M., Ma J. (2015). Fibrous nano-silica supported palladium nanoparticles: An efficient catalyst for the reduction of 4-nitrophenol and hydrodechlorination of 4-chlorophenol under mild conditions. Catalysis Communication, 59: 21-25.

[14] Dong, Z., Le, X., Li, X., Zhang, W., Dong, C., Ma, J. (2014). Silver nanoparticles immobilized on fibrous nano-silica as highly efficient and recyclable heterogeneous catalyst for reduction of 4-nitrophenol and 2-nitroaniline. Applied Catalystic B: Environmental, 158: 129-135.

[15] Hamid, M.Y.S., Firmansyah, M.L., Triwahyono, S., Jalil, A.A., Mukti, R.R., Febriyanti, E., Suendo, V., Setiabudi, H.D., Mohamed, M., Nabgan, W. (2017). Oxygen vacancy-rich mesoporous silica KCC-1 for $\mathrm{CO}_{2}$ methanation. Applied Catalysis A: General, 532: 86-94
[16] Ahmaruzzaman, M., Gupta, V.K. (2011). Rice Husk and Its Ash as Low-Cost Adsorbents in Water and Wastewater Treatment. Industrial and Engineering Chemistry Research, 50(24): 13589-13613.

[17] Yilmaz, M.S., Piskin, S. (2015). The removal of template from SBA-15 samples synthesized from different silica sources, Journal of Thermal Analysis and Calorimetry, 121(3): 12551262 .

[18] Nayak, J.P., Bera, J. (2011). Preparation of an efficient humidity indicating silica gel from rice husk ash. Bulletin of Materials Science, 34(7): 1683-1687.

[19] Kumchompoo, J., Wongwai, W., Puntharod, R. (2017). Microwave-Assisted Preparation of Sodium Silicate as Biodiesel Catalyst from Rice Husk Ash. Key Engineering Material, 751: 461-466.

[20] Pereira, S.A.P., Costa, S.P.F., Cunha, E., Passos, M. L.C., Araújo, A.R.S.T., Saraiva, M.L.M.F.S. (2018). Manual or automated measuring of antipsychotics' chemical oxygen demand, Ecotoxicology and Environmental Safety, 152: 55-60.

[21] Matori, K., Haslinawati, M.M., Wahab, Z.A., Ban, T.K. (2009). Producing Amorphous White Silica from Rice Husk. Journal of Basic Applied Science, 1(3): 512-515.

[22] Bakar, R.A., Yahya, R., Gan, S.N. (2016). Production of High Purity Amorphous Silica from Rice Husk. Procedia Chemistry, 19: 189-195.

[23] Shoppert, A.A., Loginova, I.V., Chaikin, L.I., Rogozhnikov, D.A. (2017). Alkali FusionLeaching Method For Comprehensive Processing Of Fly Ash. KnE Material Science, 2(2): 89-96.

[24] Sousa, A.M. de Visconte, L., Mansur, C., Furtado, C. (2009). Silica sol obtained from rice husk ash. Chemistry and Chemical Technology, 1-6.

[25] Keawthun, M., Krachodnok, S., Chaisena, A. (2014). Conversion of waste glasses into sodium silicate solutions. International Journal of Chemical Science, 12(1): 83-91.

[26] da Silva, R.J.F, Dutra, A.J.B., Afonso, J.C. (2012). Hydrometallurgy Alkali fusion followed by a two-step leaching of a Brazilian zircon concentrate. Hydrometallurgy, 117, 93-100.

[27] Shelke, V.R., Bhagade, S.S., Mandavgane, S.A. (2010). Mesoporous Silica from Rice Husk Ash. Bulletin of Chemical Reaction Engi-Neering \& Catalysis, 5(2): 63-67.

[28] Ouyang, M., Wang, Y., Zhang, J., Zhao, Y., Wang, S., Ma, X. (2016). Three dimensional $\mathrm{Ag} / \mathrm{KCC}-1$ catalyst with a hierarchical fibrous 
framework for the hydrogenation of dimethyl oxalate. RSC Advances, 6(16): 12788-12791.

[29] Polshettiwar, V., Cha, D., Zhang, X., Basset, J.M. (2010). High-surface-area silica nanospheres (KCC-1) with a fibrous morphology. Angewandte, 49(50): 9652-9656.

[30] Wang, J., Fang, L., Cheng, F., Duan, X., Chen, R. (2013). Hydrothermal Synthesis of SBA-15 Using Sodium Silicate Derived from Coal Gangue. Journal of Nanomaterials, 1-6.

[31] Ekka, B., Rout, L., Kumar, M.K.S.A., Patel, R.K., Dash, P. (2015). Removal efficiency of $\mathrm{Pb}$ (II) from aqueous solution by 1-alkyl-3methylimidazolium bromide ionic liquid mediated mesoporous silica. Journal of Environmental Chemical Engineering, 3(2): 13561364.

[32] Dong, Z., Le, X., Dong, C., Zhang, W., Li, X., Ma, J. (2015). Ni@Pd core-shell nanoparticles modified fibrous silica nanospheres as highly efficient and recoverable catalyst for reduction of 4-nitrophenol and hydrodechlorination of 4-chlorophenol. Applied Catalystic B: Environmental, 162: 372-380.

[33] Gang, T.A.N., Yongjie, X.U.E., Jun, C.A.I. (2015). Isotherm study on adsorption removal of $\mathrm{Pb}$ ( II ) by MCM-41 zeolite synthesized from biomass ash. Atlantis Press, (Iccset 2014), 91-96.

[34] Salman, T., Temel, F.A., Turan, N.G., Ardali, Y. (2015). Adsorption of lead (II) ions onto diatomite from aqueous solutions: Mechanism, isotherm and kinetic studies. Global NEST Journal, 18(1): 1-10.

[35] Wu, X., Chen, Z., Luo, L., Li, L., Liu, Y. (2016). Adsorption of Lead with Silica Gel Modified with Polyamidoamine Dendrimer and Thiomalic Acid. MATEC Web of Conferences, 67: 06099.
[36] Kavitha, K.K.R. (2015). Convenient Synthesis of Micron-sized Macro Porous Polymers with Silica on their Surfaces and Excellent Adsorption Performance for $\mathrm{Pb}$ (II) Ion. Journal of Environmental \& Analytical Toxicology, 05(04), 1-7.

[37] Košak, A., Lobnik, A., Bauman, M. (2015). Adsorption of mercury(II), lead(II), cadmium(II) and zinc(II) from aqueous solutions using mercapto-modified silica particles. International Journal of Applied Ceramic Technology, 12(2): 461-472.

[38] Jamhour, R.M.A.Q., Ababneh, T.S., Alrawashdeh, A.I. (2016). Adsorption Isotherms and Kinetics of $\mathrm{Ni}$ (II) and $\mathrm{Pb}$ (II) Ions on New Layered Double Hydroxides Nitrilotriacetate Composite in Aqueous Media. Advances in Analytical Chemistry, 6(1): 17-33.

[39] Vijayalakshmi, K., Devi, B.M., Latha, S., Gomathi, T., Sudha, P.N., Venkatesan, J., Anil, S. (2017). Batch adsorption and desorption studies on the removal of lead (II) from aqueous solution using nanochitosan/sodium alginate/microcrystalline cellulose beads. International Journal of Biological Macromolecules, 104: 1483-1494.

[40] Abdul-Raheim, A.-R.M., Shimaa, E.-S.M., F.R.K, Manar, A.-R.E. (2016). Low Cost Biosorbents Based On Modified Starch Iron Oxide Nanocomposites For Selective Removal Of Some Heavy Metals From Aqueous Solutions. Advance Material Letter, 7(5): 402-409.

[41] Luo, S., Lu, T., Peng, L., Shao, J., Zeng, Q., $\mathrm{Gu}$, J.D. (2014). Synthesis of nanoscale zerovalent iron immobilized in alginate microcapsules for removal of $\mathrm{Pb}$ (II) from aqueous solution. Journal of Material Chemistry A, 2(37): 15463-15472.

[42] Dolphen, R., Thiravetyan, P. (2011). Adsorption of melanoidins by chitin nanofibers. Chemical Engineering Journal, 166(3): 890895.

Selected and Revised Papers from The $4^{\text {th }}$ International Conference of Chemical Engineering $\&$ Industrial Biotechnology (ICCEIB 2018) (http://icceib.ump.edu.my/index.php/en/) (Universiti Malaysia Pahang, by 1st_2nd August 2018) after Peer-reviewed by Scientific Committee of ICCEIB 2018 and Peer-Reviewers of Bulletin of Chemical Reaction Engineering \& Catalysis 